\title{
Gender Differences in Competition
}

\author{
Muriel Niederle and Lise Vesterlund
}

\begin{abstract}
Negotiating in a bighly competitive environment may prove particularly challenging for women. We describe three experimental studies that investigated and documented differences in the competitive behaviors of men and women. The first study examined gender differences in competitive performances. In a setting in which men and women performed at similar levels in single-sex competitions, men were found to outperform women in mixed-sex competitions. The second study focused on the decision of men and women to enter a competition. In a mixed-sex setting in which we found no gender differences in performance, many more men than women chose a compensation scheme in which they had to compete against otbers. Finally, we report the results of a recent study that examined an institutional intervention that may encourage more women to compete. Specifically, we found that a quota-like affirmative action environment in which women must be equally represented encourages many more women to compete. This response was greater than one would predict based solely on the increase in one's chances of winning and can be partially explained by the fact that the affirmative action competition was more gender specific.
\end{abstract}

Muriel Niederle is an associate professor of economics at Stanford University and faculty research fellow at the National Bureau of Economic Research (NBER). Her e-mail address is niederle@ stanford.edu.

Lise Vesterlund is the Andrew W. Mellon Associate Professor of Economics at the University of Pittsburgh. Her e-mail address is vester@pitt.edu. 
Key words: negotiation, gender differences, competition, confidence.

\section{Introduction}

Across fields there remains substantial vertical segregation between men and women. A disproportionate number of professional and managerial senior positions are held by men. In a large sample of firms in the United States, Marianne Bertrand and Kevin Hallock (2001) found that women accounted for only 2.5 percent of the five highest paid executives. Similarly only about 17 percent of partnerships at major law firms nationwide were held by women in 2005 (O'Brien 2006).

Standard explanations for such differences have included discrimination and gender differences in preferences and ability. Discrimination or anticipated discrimination may prevent women from breaking through what has come to be known as the "glass ceiling." ${ }^{1}$ Second, women may not choose to pursue more competitive high-profile jobs because they do not enjoy the responsibilities or the long work hours associated with a managerial position. Finally, men and women may differ in their abilities to master the skills required for high-ranking positions. ${ }^{2}$ In this article, we report on a fourth explanation for why fewer women than men may be found in competitive and high-profile jobs: the behavior of men and women may differ in competitive environments.

An individual's behavior in a competitive environment can play an important role in his or her occupational experiences. Certainly, because most negotiations are inherently competitive, the attitude toward competition can influence negotiated outcomes. Negotiators may compete for the larger share of the pie in distributive negotiations, or they may compete with other negotiators in the same role for access to scarce resources or for a relatively better deal.

Nurture as well as nature have been used as explanations for why men and women may differ in their competitive behaviors. First, we have tended to raise girls and boys differently. Parents, teachers, and peers have traditionally encouraged gender-typed activities in children, while cross-gender activities have been discouraged. Boys are encouraged to be assertive, whereas girls are encouraged to show empathy and be egalitarian (Ruble, Martin, and Berenbaum 2006).

Second, nature may cause preferences for competition to differ between men and women. Evolutionary psychologists have proposed two theories to explain why men may have evolved to enjoy competition; both are tied to the reproductive strategies of the two sexes. One theory is that, because men can have many more children than women, the potential gain in reproductive success from winning a competition is much greater for 
men, and men have therefore evolved to be more competitive than women (Daly and Wilson 1983). The second theory focuses on one gender being responsible for parental care. While a man's death does not diminish his current reproductive success, a woman's death may cause the loss of her current offspring (Campbell 2002), increasing the cost associated with competitive behavior. Thus differences in losses as well as gains from competition may make males relatively more eager to compete.

If, as a result of either nature or nurture or both, competition imposes psychic costs on women while men receive a psychic benefit, then competitive behavior may differ substantially by gender. We report on three different studies that investigated such differences. The first study examined whether the competitive performance of men and women may differ. The second study sought to determine if, for any given performance, men may be more likely to enter competitive environments such as a competitive negotiation. Finally, in the third and last study, we investigated if affirmative action is an institution that may circumvent these differences.

Because a negotiation can be viewed as a competition over scarce resources, our results also shed light on gender differences relevant to people's ability and willingness to negotiate. Indeed our results are very much in line with that of the negotiation literature. For example, Hannah Riley Bowles, Linda Babcock, and Kathleen McGinn (2005) found that men perform better in negotiations that trigger competition, and Babcock and Sara Laschever (2003) found that women can be more reluctant to negotiate than men. Similarly, Fiona Greig (2008; in this issue) found that gender differences in willingness to ask have real economic consequences and help explain gender differences in career advancement.

To establish the existence of gender differences in competitive environments, we conducted laboratory experiments. These experiments have several benefits over existing data in the field. Specifically, we can precisely measure performance, eliminate any discrimination, and rule out the impact of possible gender differences in preferences concerning such issues as time commitment and child rearing, which often come into play in real-life settings.

We first present the results of a study by Uri Gneezy, Muriel Niederle, and Aldo Rustichini (2003). They conducted experiments in an environment in which they found no gender differences in performance when subjects performed under a noncompetitive piece-rate compensation scheme in which individuals were paid for each correctly solved problem. Nonetheless, men outperformed women in a competitive environment when only the best performing person was paid. Although this evidence from a mixed-sex setting suggests that women are less competitive than men, results from a single-sex setting reveal that such a conclusion is exaggerated. Indeed in single-sex tournaments, the performance of women mirrored that of men. Hence, women are as competitive as men when competing against women, but not when competing against men. 
Even if some women perform well in a competition against men, it is not clear that such women are as likely as men to enter a competition. In the second study (Niederle and Vesterlund 2007), we examined an environment in which we found no gender differences in competitive performances. Nonetheless, women were much more likely than men to select a noncompetitive piece rate over a competitive tournament scheme. While some of this gender gap in willingness to compete is explained by the fact that men are substantially more overconfident about their relative ability, the remainder is accounted for by gender differences in attitudes toward competition. While men embraced the competition, the women shied away from it. Consequently, fewer women competed in and won the tournament.

From a firm's perspective it can be particularly costly if some of its higher level, higher achieving personnel do not compete for jobs or promotions or if they fail to negotiate for such promotions. Indeed American corporations are concerned about their inability to recruit and retain women, and they are increasingly developing programs to increase the number of women employees. ${ }^{3}$ To create effective programs to alter the gender composition of certain professions, it is necessary to understand how these programs influence behavior. The third study we describe is our recent collaboration with Carmit Segal (Niederle, Segal, and Vesterlund 2008). In this study, we sought to illuminate how programs such as affirmative action can affect an individual's willingness to compete. Specifically, we found that a quota-like affirmative action environment in which women must be equally represented encourages more women to compete, a response that is in part explained by the fact that a quota makes the competition more gender specific.

\section{Performance in Competitive Environments}

The first economic experiments on gender differences in competitive attitudes tested whether women and men react differently to competitive incentive schemes. Specifically, the question was whether gender differences in performance are exacerbated in competitive tournament environments compared to noncompetitive piece-rate incentive schemes.

Gneezy, Niederle, and Rustichini (2003) conducted an experiment at the Technion, the most competitive technology university in Israel. A selective characteristic of women enrolled at Technion is their willingness to study in a predominantly male domain and environment. In the experiment, women and men were asked to solve mazes on the Internet for fifteen minutes under various incentive schemes. In each session, three women and three men solved the task. They could see each other and thus determine the gender composition of the group, though gender was not explicitly mentioned. Thirty women and thirty men participated in each scenario. No one participated more than once. At the end of the experiment participants were informed only about their own earnings. 
In the first noncompetitive piece-rate scenario, each participant received a fixed prize for every solved maze (about fifty cents per completed maze). That is, the payment was independent of the performance of other participants in the same group. On average, men completed 11.23 mazes, while women, on average, completed 9.73 , resulting in a small and statistically insignificant gender performance difference of 1.5 mazes.

The second incentive scheme was a tournament: of the three men and three women in each group, only the participant with the highest performance - the person who won the tournament - received a payment. The other participants received no payment. The tournament winner received a payment of three dollars for every maze that he or she solved.

In this scenario, the men, on average, solved fifteen mazes, a number significantly greater than the 11.23 maze average of the men in the noncompetitive version of the experiment. Thus, men seem to react strongly to competition and increase their performance in this mixed-sex tournament.

By contrast, the women in the tournament solved, on average, 10.8 mazes - a number that was much lower than the fifteen mazes solved by men. Even more noteworthy is that the difference between the performance of the men and of the women increased to 4.2, which substantially exceeded the average performance difference of 1.5 mazes in the noncompetitive environment. Furthermore, the performance of women in the competitive environment, 10.8, was not much better than the noncompetitive environment performance of 9.73 . The absence of a significant change in performance for women contrasts sharply to the substantial improvement of the score for the men, which increased from the piece-rate condition to the tournament condition by 3.77 mazes.

The performance of women and men was similar in a noncompetitive environment, but as the environment became competitive, men seemed to react strongly to competition and to improve their performance substantially. In contrast, the performance of women did not change. As a result, we found a large gender difference in performance in the competitive environment. ${ }^{4}$

\section{Is the Differential Response to Competition Explained by Uncertainty?}

Before we could associate the significant increase in the gender gap of performance to gender differences in reaction to competition, we controlled for another difference between the piece rate and the competitive pay treatment. The payment in the piece rate scheme is certain, while it is uncertain in the competitive environment. It is possible that the gender differences in performance that we found were driven by gender differences in reactions to the uncertain payment schemes, rather than to the competitive payment schemes. ${ }^{5}$ 
We conducted an experiment in which the payment scheme in terms of uncertainty was similar to the competitive pay treatment, with only one participant receiving a compensation of six times the piece rate scheme, but without any competitive aspect because the payment recipient - the "winner" - was chosen randomly. In this scenario the average performances of women and men, and the differences between their average performances, were similar to their performances in the first piece-rate payment scenario. Thus, we determined that it was not uncertainty in payment itself that generated a gender difference in performance, but rather the gender gap in mixed tournaments can be attributed to gender differences in the response to competition.

\section{Why Are There Gender Differences in Competitive Performance?}

We suggest three classes of explanations for why women and men differ in their response to competition. First, it could be that women do not perform well in a competition in general because they cannot or do not like to compete. Perhaps women would have to incur high costs to increase the number of mazes they would solve in a competitive scenario. Second, it could be that women will compete, but not against men. An explanation may be that women perform less well in this task than men, and this difference could be exacerbated by their belief that relative to men they are less adept at this particular skill. That is, women may believe that they do not have a good chance of winning, and hence simply do not try as hard. Third, an alternate view would look not at the performance deficit of women but at the performance excess of men. In this view, men may be seen as competing too much and thus working too hard for the prize of winning.

In a final version, participants competed in single-sex tournaments, in groups of either six men or six women. The results suggest that women will indeed compete against other women. In the single-sex tournaments, the average performance of men was 14.3 mazes, which is not significantly different from men's average performance of fifteen in the previous competitive scenario, though greater than the average male performance in the noncompetitive piece-rate environment. That is, it does not appear that men compete only when they are competing against women.

But more importantly, in this version we found that women were more competitive: their average performance in the single-sex tournament was 12.6, which was higher than the average female performance in the piecerate environment.

To compare whether women responded to competitive incentive schemes in single-sex groups as much as men did, we compared the average gender differences in performance across treatments. The gender gap in 


\section{Figure One}

Average Performance of Thirty Men and Thirty Women in Each Treatment

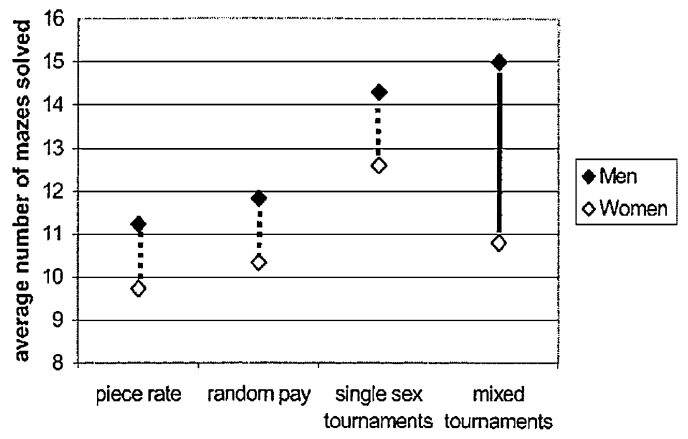

performance was 1.5 mazes in both the piece-rate and the random-pay treatment and 1.7 mazes in the single-sex tournament. The gender gap in mean performance, however, was 4.2 in mixed tournaments, significantly higher than in all other treatments. Figure One shows for women and men the average performance under each incentive scheme. It illustrates that the gender difference in performance is indeed very similar under all treatments, with exception of the mixed-sex tournaments in which we found a large gender gap in performance.

We found a significantly larger gender gap in mixed-sex competitive environments compared to either a noncompetitive piece rate or a singlesex competitive environment. This difference is driven largely by women's failure to perform at a high level when competing against men.

\section{Entering Competitive Environments}

The finding that women, while able to compete, failed to do so in competition against men suggests that women's attitudes toward competition may differ from those of men. Such attitudinal differences may cause not only gender differences in performance in mixed-sex competitions but also differences in the likelihood that men and women will enter competitive environments. If women feel uncomfortable performing in a competitive setting then they may be less likely to place themselves in one. A first-order explanation for not observing women in competitive environments or competitive negotiations may therefore be that they choose not to engage in competition.

The second study we report on (Niederle and Vesterlund 2007) examined whether men and women differ in their willingness to compete. 
We studied compensation choices in a mixed-sex environment. In this experiment, forty men and forty women were asked to perform a task under varying compensation schemes. To better identify gender differences in compensation choices, we selected a task for which we anticipated a small difference in competitive performance. We chose a relatively short task because we thought it would be easier for participants to maintain high performance levels throughout the task and to reduce the chances that a gender difference in response to initial failure would have a substantial effect on overall performance.

We chose a task in which both women and men would perform well, asking participants to solve a series of cross sums. While males often score better on abstract math problems, women tend to score better than men on computational problems (see Hyde, Fennema, and Lamon 1990 for a metaanalysis of one hundred studies on gender differences in math performance) ${ }^{6}$ In the task, participants were given five minutes during which they were asked to add up five sets of two-digit numbers. The participant's score for each task was the number of correctly solved problems. ${ }^{7}$ We never mentioned gender during the course of the experiment. Participants were informed that they would be asked to perform four different tasks during the experiment but were given no details about each task until immediately before they were asked to do it. At the end of each task, we informed them only about their own performance, providing no other feedback. Thus, they were never informed of the performance of anyone else in the study.

\section{Competitive and Noncompetitive Performances}

Participants first performed the task under a noncompetitive piece rate in which they received fifty cents per correctly solved problem. We found no gender differences in performance: the average number of correctly solved problems was 10.7 for men and $\mathbf{1 0 . 2}$ for women.

For the next task, participants competed in groups of four, two men and two women. The members of a group were seated in a row and participants could see their competitors and determine the gender composition of the group. The compensation levels in the tournament were as follows: the person with the most correctly solved problems received two dollars per correct problem, while the other members of the group received no payment. ${ }^{8}$ Once again we found no gender differences in performance. During the five-minute competitive addition task, women solved an average of 11.8 problems, while men solved 12.1 . Of the twenty groups, eleven were won by women and nine by men. Thus, for this short task men and women do not appear to differ in their ability to compete in mixed-gender groups. The increase in performance between the noncompetitive and competitive performance was most likely a result of learning rather than of increased effort in the tournament. ${ }^{9}$ 


\section{Figure Two}

\section{Proportion Selecting Tournament Conditional on Actual Initial Tournament Performance}

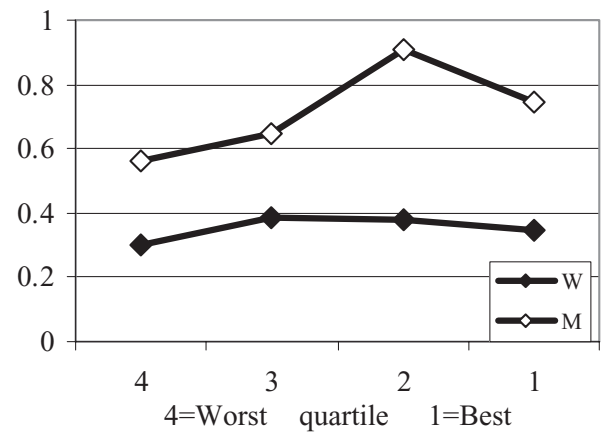

\section{Competitive Entry}

Having experienced both compensation forms but without receiving any information on relative performance, participants were then asked which compensation they would prefer for their performance on a subsequent five-minute addition task, a fifty-cent piece rate or a $\$ 2$ tournament. ${ }^{10}$ To ensure that the choice only depended on the participant's beliefs on relative performance, we designed the compensation choice as an individual decision; that is, the individual's choice was in no way affected by the choices made by the other group members. Specifically, a participant who selected the tournament would win if his or her subsequent performance exceeded the previous competitive performance of the three other group members.

Because the men and women had similar performances and hence had identical experiences performing the first two tasks, we should not have expected the compensation choices to differ by gender. If the subsequent tournament performance was like the initial one, then 30 percent of women and 30 percent of men would have received higher earnings from a tournament payment scheme. That is, we would predict no gender difference in choice of compensation scheme if participants made choices that maximized their earnings. But we found that the majority of men chose the tournament scheme and the majority of women chose the piece rate. While 73 percent of men entered the tournament, only 35 percent of women made this choice. ${ }^{11}$

From our discussion above it is clear that performance alone cannot explain these large gender differences. Figure Two shows, for each initial tournament performance quartile, the proportion of participants who enter 
the subsequent tournament. The tournament-entry decisions of neither men nor women were very sensitive to the individual's performance. Independent of the performance quartile in which their performance placed them, men were much more likely to enter the tournament than women. Even women in the highest performance quartile, who have a good chance of winning the tournament, were less likely to enter the tournament than men in the lowest performance quartile, who basically had no chance of winning. We obtained similar results when we considered the performance after the entry decision rather than the one before the entry decision.

\section{Why Are There Gender Differences in Competitive Entry?}

One explanation for women's relative reluctance to enter the tournament involves gender differences in beliefs on relative performance. While individuals typically are found to be overconfident about their relative ability (in all areas), men tend to be more overconfident than women (see, e.g., Lichtenstein, Fischhoff, and Phillips 1982; Beyer 1990; Beyer and Bowden 1997). Gender differences in overconfidence may help explain why men entered the tournament more than women. To assess this potential explanation, we elicited participants' beliefs about their relative performance in the initial competitive tournament scheme.

We asked each participant to guess his or her performance rank in their group; a correct guess was rewarded by one dollar. Consistent with previous studies, we found that both men and women were overconfident about their relative abilities, but that this phenomenon was much more pronounced among men. When asked to guess their rank in a group of four, thirty out of forty men ( 75 percent) reported that they thought that they were the best in their group. With seventeen out of forty women (43 percent) guessing that they were first, women were also overconfident, but much less so than their male counterparts.

For both men and women, beliefs play a significant role in predicting whether they chose the competitive option, and indeed the greater male overconfidence helps explain the gender gap in tournament entry. A substantial gender gap remains, however, even after controlling for these beliefs. This is easily seen in Figure Three. Among those who reported that they thought they were best in their group of four, 80 percent of men entered the tournament compared to only 50 percent of women. Similarly the 30-percentage-point gender gap in tournament entry persisted among those who thought they were second best out of four. With 84 percent of participants of both sexes reporting that they were ranked first or second, conditional on beliefs we still found a substantial gender gap in competitive entry for the vast majority of our participants.

Another explanation for the different compensation choices made by men and women is that they may differ in their attitudes toward risk and 
Figure Three

Proportion Selecting Tournament Conditional on Believed Performance Rank in Initial Tournament

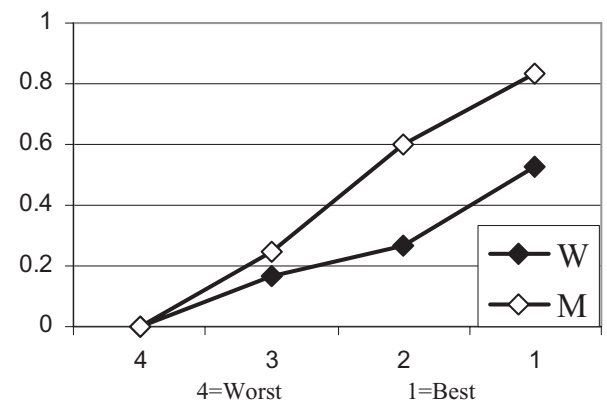

feedback on relative performance. Research suggests that women may be more averse to risky outcomes, and that, in contrast to men, they internalize negative feedback (see, e.g., Roberts and Nolen-Hoeksema 1989). The compensation scheme associated with the tournament is not only more risky, but also involved receiving feedback on relative performance. In our study, however, we found little evidence to suggest that these factors play a major role in explaining gender differences in the choice to enter the tournament. Having controlled for the effects of beliefs about relative performance, risk aversion, and feedback aversion, a substantial and significant gender difference remains in the decision to enter the tournament or not. ${ }^{12}$ We attribute this remaining difference to men's and women's differing attitudes toward placing themselves in environments where they have to compete against others.

Thus, the study documents substantial gender differences in compensation choices. Two explanations for these differences are that men are more overconfident than women and that men and women have different preferences for placing themselves in a competitive environment. While women seem to shy away from competition, men appear to embrace it. A consequence is that from a payoff-maximizing perspective, too few highperforming women and too many low-performing men entered the tournament. By selection alone we found very few women succeeding in and winning the tournament.

\section{Can We Entice Women to Compete?}

Our results demonstrate significant gender differences in competitive behavior. In mixed-gender environments in which there appear to be no gender differences in ability, men may nonetheless outperform women and 
more frequently select a competitive compensation. We can draw a strong parallel between the two research findings. One possible explanation for the lower performance of women in the mixed-sex tournaments seen in the first study (Gneezy, Niederle, and Rustichini 2003) is that the women chose not to compete. While this was not an explicit choice, the finding that there were no gender differences in performance in the noncompetitive environments nor in the single-sex competitions both suggest that women did not perform to their maximal ability in the mixed-sex competition. Thus, we can view the lower competitive performance of the women in mixed-sex groups as reflecting their choice not to compete.

This parallel suggests that, in considering how to encourage women to compete, we need to remember that we found no gender differences in performance in the single-sex competition. To the extent that women are less intimidated by more gender-specific competitions, it may be possible to alter the procedure by which we select tournament winners to encourage more women to compete.

In a third study, we collaborated with Carmit Segal to study this possibility (Niederle, Segal, and Vesterlund 2008). Specifically we examined the compensation choices of men and women in an affirmative action tournament, where for every two winners we required that at least one winner must be a woman. Such a requirement not only increased the probability that women would win the tournament, it also made the competition more gender specific. For example, under this rule a woman would win the competition if she performed better than her female competitors.

Using a sample of forty-two women and forty-two men, we compared two compensation choices for a future five-minute addition task. Participants competed in groups of three men and three women. In one scenario, participants were asked to choose between a fifty-cent piece rate and a tournament in which the two participants who solve the largest number of problems each would be paid $\$ 1.50$ per correctly solved problem and the remaining four members would receive no payment. (This task is similar to the one in our second study, Niederle and Vesterlund 2007, described earlier.) In the second scenario, participants were instead asked to choose between a fifty-cent piece rate and a $\$ 1.50$ affirmative action tournament. The two winners of the affirmative-action tournament would be the highest performing woman and the highest performer, male or female, of the remaining five members of the group.

\section{How Does Affirmative Action Affect Competitive Entry?}

The introduction of the affirmative action tournament not only increased the probability that a woman would win the competition, but it also made the competition more gender specific. In the affirmative action tournament, a woman would win the competition if she was either the best-performing woman or had the second highest performance in the group; a man on the 
other hand would have to be both the best-performing man and have the second highest performance in the group. There are two reasons why a more gender-specific competition may alter the tournament-entry decisions. The gender gap in beliefs about one's abilities may be smaller in competitions that are more gender specific; the gender gap in attitudes to competition may diminish as well.

We found that, when women were guaranteed equal representation among winners, more women and fewer men chose to compete, and the change exceeded that predicted by changes in the probability of winning. The excessive response can be explained by beliefs on rank and attitudes toward competition that changed in more gender-specific competition. Specifically, it appears that men become less overconfident and women less reluctant to compete in groups in which their competitors are more likely to be of their own gender.

\section{How Costly Is Affirmative Action?}

What are the costs of introducing the affirmative action requirement that women at least be equally represented? Suppose we do not expect changes in tournament entry. Prior to the introduction of affirmative action in our studies, we found that few high-performing women chose to enter a (mixed-sex) competition. This implies that the expected costs of affirmative action on this pool are large. For example, in order to select (at least) one woman for every man, there are only two options. Either almost no one gets "hired" because so few women enter a mixed competition, or the performance threshold would have to be reduced substantially in order to select a woman, and a large number of better performing men would have to be passed by.

But the introduction of the affirmative action resulted in a large increase in the number of women who chose to compete, including many high-performing women. The effect was so large that for most performance thresholds the equal representation requirement was not binding. That is, the costs of affirmative action in terms of hiring lower performing women or passing by many better men to hire an additional woman would not be incurred because there would now be many more high-performing women from whom to choose.

Thus, changes in willingness to compete have important implications when assessing the costs of affirmative action. Absent a change in entry, affirmative action is predicted to lower the performance requirement for women and thus result in reverse discrimination toward men. This need not be the outcome, however, when entry is suboptimal before affirmative action, with many high-performing women not opting into the tournament. The significant response of women to affirmative action, namely, the large increase in the number of all women, including high-performing women who chose to compete in the tournament, implies that it may not be 
necessary to lower the performance requirement for women in order to achieve a more diverse set of winners.

\section{Conclusion and Summary}

We have discussed three studies that all demonstrate substantial gender differences in competitive behavior. First, in an environment in which women did well when competing against other women, they appeared to underperform when competing against men. Second, conditional on performance, men and women were found to differ substantially in their willingness to enter a mixed-sex competition. While men seemed eager to compete, women appeared to shy away from the competition. Our results suggest that the main explanations for the gender difference in competitive entry are that men are more overconfident about their relative ability and that women are more averse to competing.

In the third study, we demonstrated that changes in these two factors alter the gender difference in competitive entry. In particular we saw that in an affirmative action setting in which one woman would be hired for every man, the competition becomes more gender specific, in turn causing the gender difference in overconfidence to disappear; in addition, women become much less reluctant to compete when doing so in an all-female competition. This resulted in a large increase of high-performing women who entered a tournament, making affirmative action a policy that was not very costly in this setting.

These insights may help explain why men and women differ in their negotiated outcomes and in their willingness to undertake a negotiation (see, e.g., Babcock and Laschever 2003; Bowles, Babcock, and McGinn 2005). Likewise, insights from the negotiation literature may shed light on circumstances in which the gender differences in competitive behavior may be relatively small. For example, meta-analytic research on gender in negotiation suggests that women are more competitive when there is less potential for communication with other parties (Walters, Stuhlmacher, and Meyer 1998; Stuhlmacher, Citera, and Willis 2007), presumably because they are more relieved from gendered social roles. Perhaps this relief from gendered roles helps explain why the response to single-sex competition differs from that of mixed-sex competition. Similarly the finding by Bowles and McGinn (2008; in this issue) that gender effects in competitive negotiation performance are diminished with reduced ambiguity suggests that the gender gap in competitive entry may be reduced when participants get clear feedback on relative performance.

The research in this article expands our understanding of gender differences in competition. It suggests new ways of thinking about institutional and organizational design to achieve the highest performance possible from both women and men. We hope that these studies will provide insights that can help us understand gender differences in competitive 
attitudes and potentially design institutions in which workers are employed in the jobs that they do best.

The documented gender differences in competition suggest that it may be particularly challenging for women to be involved in competitive negotiations, including distributive negotiations in which one negotiator's gain is the other's loss, as well as those negotiations involving same-side competition. Our results suggest that women are less likely to ask to be considered for a promotion or to be nominated by their political parties, not only because they dislike asking but because they dislike competing with others.

\section{NOTES}

1. See Altonji and Blank (1999), Goldin and Rouse (2000), Black and Strahan (2001), and references therein.

2. While ability differences may account for the lack of women in certain professions and ranks, there is no consensus on the extent to which such differences translate into an occupational gender gap. For a discussion on self-selection, see Polachek (1981).

3. For example, corporations such as Ernst and Young, Goldman Sachs, IBM, and PricewaterhouseCoopers have all adopted substantial female retention and attraction programs (see, e.g., The Economist 2005).

4. Gneezy and Rustichini (2004) documented similar results in forty-meter running competitions among ten-year-olds. The children first ran forty meters separately and then were paired off according to speed, with the two fastest children competing against one another and so on. The researchers found no initial gender difference in speed. But in general, boys won the competition against girls, whether the girl was initially slower or faster. In homogenous groups, the winner is about as often the faster or slower kid when both runners were girls or boys.

5. In summarizing the experimental literature in economics, Eckel and Grossman (Forthcoming) have concluded that women exhibit greater risk aversion in choices. In a summary of the psychology literature (Byrnes, Miller, and Schafer 1999), researchers analyzed 150 risk experiments, determining that, while women in some situations are significantly more averse to risk, many studies found no gender difference.

6. Needless to say it is not a priori possible to determine whether a particular task will or will not result in a gender difference in competitive performance.

7. The program was written using the software zTree (Fischbacher 2007).

8. On a technical note, by paying the tournament winner by performance rather than a fixed prize, we avoid providing information about winning performances or distorting incentives for very high-performing individuals.

9. This is supported by the fact that changes in performance between the first competitive performance (Task Two) and the performance following the choice (Task Three) are independent of the chosen incentive scheme. Note that this does not imply that participants do not exert effort; rather, it appears their baseline effort is already quite high.

10. The attraction of first subjecting the participants to the two compensations is that it allows participants to experience both compensation forms and provides us with performance measures that enable us to determine which compensation choice is payoff maximizing for each participant.

11. Gneezy and Rustichini (2005) and Gupta, Poulsen, and Villeval (2005) also found that women are less willing to compete than men.

12. Instead of directly controlling for risk and feedback aversion, we asked participants to make a decision between two incentives schemes that mimicked both the uncertainty in payment and the provision of feedback in a choice between a piece rate and a competition, without any actual competition taking place. In a final task, participants decided whether they wanted to apply the piece rate or tournament incentive scheme to their initial piece rate performance. The tournament choice resulted in payment only if the participant's piece-rate performance exceeded that of the three other members of the group. This choice mimics the first compensation choice, 
while eliminating the requirement of a subsequent tournament performance. This approach is reminiscent of the choice in Gneezy, Niederle, and Rustichini (2003) in which the random pay treatment induced risk similar to the competitive payment scheme while eliminating the competitive component.

\section{REFERENCES}

Altonji, J. G. and R. Blank. 1999. Race and gender in the labor market. In Handbook of labor economics. Vol. 3c, edited by O. Ashenfelter and D. Card. Amsterdam: Elsevier Science B.V.

Babcock, L. and S. Laschever. 2003. Women don't ask: Negotiation and the gender divide. Princeton, NJ: Princeton University Press.

Bertrand, M. and K. F. Hallock. 2001. The gender gap in top corporate jobs. Industrial and Labor Relations Review 55(1): 3-21.

Beyer, S. 1990. Gender differences in the accuracy of self-evaluations of performance. Journal of Personality and Social Psychology 59(5): 960-970.

Beyer, S. and E. M. Bowden. 1997. Gender differences in self-perceptions: Convergent evidence from three measures of accuracy and bias. Personality and Social Psychology Bulletin 23: 157172.

Black, S. and P. E. Strahan. 2001. The division of spoils: Rent-sharing and discrimination in a regulated industry. American Economic Review 91(4): 814-831.

Bowles, H. R., L. Babcock, and K. L. McGinn. 2005. Constraints and triggers: Situational mechanics of gender in negotiation. Journal of Personality and Social Psychology 89: 951-965.

Bowles, H. R. and K. L. McGinn. 2008. Gender in job negotiations: A two-level game. Negotiation Journal 24(4): 393-410.

Byrnes, J. P., D. C. Miller, and W. D. Schafer. 1999. Gender differences in risk taking: A meta-analysis. Psychological Bulletin 125: 367-383.

Campbell, A. 2002. A mind of her own: The evolutionary psychology of women. Oxford: Oxford University Press.

Daly, M. and M. Wilson. 1983. Sex, evolution, and bebavior, 2nd edn. Belmont, CA: Wadsworth Publishing Company.

Eckel, C. C. and P. J. Grossman. Forthcoming. Sex and risk: Experimental evidence. In Handbook of experimental economics results, edited by C. R. Plott and V. L. Smith. Amsterdam: Elsevier Science.

Fischbacher, U. 2007. Z-Tree: Zurich toolbox for ready-made economic experiments. Experimental Economics 102: 171-178.

Gneezy, U., M. Niederle and A. Rustichini. 2003. Performance in competitive environments: Gender differences. Quarterly Journal of Economics 118(3): 1049-1074.

Gneezy, U. and A. Rustichini. 2004. Gender and competition at a young age. American Economic Review Papers and Proceedings May: 377-381.

- - - and - - . 2005. Executive versus teachers: Gender, competition and self-selection. Working Paper.

Goldin, C. and C. Rouse. 2000. Orchestrating impartiality: The impact of blind auditions on female musicians. American Economic Review 90(4): 715-741.

Greig, F. 2008. Propensity to negotiate and career advancement: Evidence from an investment bank that women are on a "slow elevator." Negotiation Journal 24(4): 495-508.

Gupta, N. D., A. Poulsen, and M.-C. Villeval. 2005. Male and female competitive behavior Experimental evidence. GATE Working Paper, Ecully, France.

Hyde, J. S., E. Fennema, and S. J. Lamon. 1990. Gender differences in mathematics performance: A meta-analysis. Psychological Bulletin 107: 139-155.

Lichtenstein, S., B. Fischhoff, and L. Phillips. 1982. Calibration and probabilities: The state of the art to 1980. In Judgment under uncertainty: Heuristics and biases, edited by D. Kahneman, P. Slovic, and A. Tversky. Cambridge: Cambridge University Press.

Niederle, M., C. Segal, and L. Vesterlund. 2008. How costly is diversity? Affirmative action in light of gender differences in competitiveness. Working paper, University of Pittsburgh Department of Economics.

Niederle, M. and L. Vesterlund. 2007. Do women shy away from competition? Do men compete too much? Quarterly Journal of Economics 122(3): 1067-1101. 
O'Brien, T. 2006. Up the down staircase. The New York Times. March 19. Available from http:// www.nytimes.com/2006/03/19/business/yourmoney/19law.html.

Polachek, S. W. 1981. Occupational self-selection: A human capital approach to sex differences in occupational structure. Review of Economics and Statistics 63: 60-69.

Roberts, T.-A. and S. Nolen-Hoeksema. 1989. Sex differences in reactions to evaluative feedback. Sex Roles 21: 725-747.

Ruble, D. N., C. L. Martin, and S. A. Berenbaum. 2006. Gender development. In Handbook of child psychology, 6th edn, edited by W. Damon and R. M. Lerner. New York: Wiley.

Stuhlmacher, A. F., M. Citera, and T. Willis. 2007. Gender differences in virtual negotiation: Theory and research. Sex Roles 57: 329-339.

The Economist. 2005. The conundrum of the glass ceiling: Women in business. The Economist July 21: 64 .

Walters, A. E., A. F. Stuhlmacher, and L. L. Meyer. 1998. Gender and negotiator competitiveness: A meta-analysis. Organizational Behavior and Human Decision Processes 76(1): 1-29. 